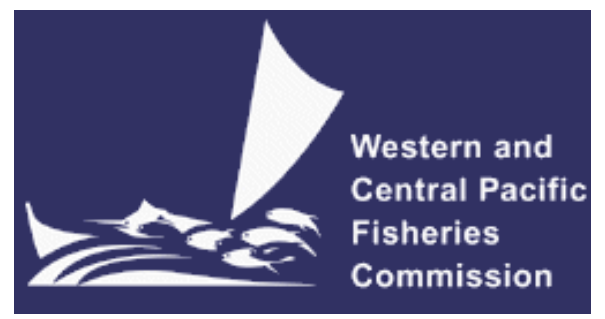

\title{
SCIENTIFIC COMMITTEE
}

THIRD REGULAR SESSION

13-24 August 2007

Honolulu, United States of America

\section{BAIT LOSS AND ITS POTENTIAL EFFECTS ON \\ FISHING POWER IN PELAGIC LONGLINE FISHERIES}

WCPFC-SC3-FT SWG/WP-6

Peter Ward $^{1}$ and Ransom A. Myers ${ }^{2}$

(reprint from Fisheries Research 86 (2007) 69-76).

\footnotetext{
${ }^{1}$ BRS, Canberra, Australia.

${ }^{2}$ Dalhousie University, Halifax, Nova Scotia, Canada.
} 


\title{
Bait loss and its potential effects on fishing power in pelagic longline fisheries
}

\author{
Peter Ward*, Ransom A. Myers \\ Department of Biology, Dalhousie University, Halifax, Nova Scotia B3H 4J1, Canada
}

Received 29 October 2006; received in revised form 5 March 2007; accepted 9 May 2007

\begin{abstract}
We analyzed 1950s survey data with generalized estimating equations (GEEs) to quantify factors that influence the rate that bait is lost from pelagic longlines. Hook depth, bait species, local tuna abundance, and the timing of longline operations strongly influenced loss rates. Loss rates increased with tuna abundance and soak time. They declined with hook depth and were low for firm-bodied bait, such as squid. Many longliners began targeting bigeye tuna with deep longlines in the mid 1970s and have used squid bait since the 1980s. This may have resulted in increased fishing power, with important implications for the estimation of abundance from catch and fishing effort data.
\end{abstract}

(C) 2007 Published by Elsevier B.V.

Keywords: Effort standardization; Fishing power; Catchability; Pelagic; Longline; Bait

\section{Introduction}

Abundance indices for pelagic fish are often derived from models based on long time-series of catch and fishing effort data. Models are used to adjust catch rates or "standardize" for factors that affect fishing power, the stock's availability, and the stock's vulnerability to the gear, e.g., time and area of fishing activity (Maunder and Punt, 2004; Bishop, 2006). For pelagic longlining, effort is taken to be proportional to the number of hooks deployed. However, the availability of baited hooks is another factor that is likely to influence catch rates or catch-perunit-effort (CPUE) of hook-and-line fishing gear (Deriso and Parma, 1987). Usually, a hook must have bait attached if it is to attract and catch an animal. Animals are caught, or they remove bait without being caught, or bait may fall off hooks (Shomura, 1955). Availability of baited hooks - and thus fishing power is expected to increase over time as fishers gain experience with different bait types, fishing methods, and gear.

Although fishers take a keen interest in the performance of their bait, data are rarely collected on bait loss. Empirical studies of pelagic longlines and bottom-set demersal longlines show that loss rates tend to increase with soak time- - how long

\footnotetext{
* Corresponding author. Present address: Fisheries and Marine Sciences, Bureau of Rural Sciences, P.O. Box 858, Canberra, ACT 2601, Australia. Tel.: +61 26272 4163; fax: +61262723882.

E-mail address: peter.ward@brs.gov.au (P. Ward).
}

baited hooks are in the water (Shomura, 1955; Shepard et al., 1975; Skud, 1978; Pingguo, 1996). Those studies indicate that loss rates vary among bait species, with soft-bodied mackerel (Scomber spp.) more likely to fall off hooks or to be torn from hooks than are firmer-bodied squid. The studies of demersal longlines also found increasing loss rates with water depth. Demersal longline surveys use standard fishing gear and practices to limit bias from factors that affect fishing power, such as soak time and bait species (Sullivan and Rebert, 1998; Sigler, 2000). Standardized surveys are rarely undertaken to estimate the abundance of pelagic fish in the open ocean because of the high cost of obtaining representative samples from a system that features vast distances and high spatial and temporal variability. As a result, assessments of pelagic species largely rely on data reported by commercial fishers in logbooks (Bishop, 2006). The effect of bait loss on the fishing power of commercial longliners has been ignored when standardizing such data because factors affecting loss rates have been assumed to be constant over time.

This article is one in a series that examine how catch rates from hook-and-line fishing gear relate to abundance and biomass. These include articles on the timing of fishing operations (Ward et al., 2004), hook depth (Ward and Myers, 2005a), and biological habitats (Ward and Myers, 2005b). The purpose of the present article is to determine what factors affect the rate of bait loss from pelagic longlines. Loss rate is the number of lost baits divided by the number deployed. Fishing power or "fishing efficiency" is formally defined as a vessel's effectiveness in 
catching animals relative to the effectiveness of a standard vessel (Beverton and Holt, 1957). The unit of effort used for calculating longline catch rates is the number of hooks deployed. We use the term fishing power to refer to the relative number of baits available. We take an empirical approach in modeling variables that affect loss rates, and then use the model to extrapolate trends in historical fishing power from information on Japanese longline gear and practices. Trends in fishing power are presented relative to the number of baits available on the longlines used when industrial longlining began in the early 1950s.

\section{Methods}

\subsection{Data}

We analyzed data from a US program of scientific surveys known as the Pacific Oceanic Fisheries Investigations (POFI). Using pelagic longline gear and techniques adopted from Japan, POFI conducted surveys each of about 2 months duration in the tropical Pacific Ocean during the 1950s (Murphy and Shomura, 1972). Most of the activity was during 1951-1953. Survey fishing was conducted as a controlled experiment where fishing gear and techniques were held constant throughout the study. Murphy and Shomura (1972) and reports that they cite provide details of survey fishing gear and techniques. Longlines were deployed in a grid at pre-determined stations. They were normally deployed
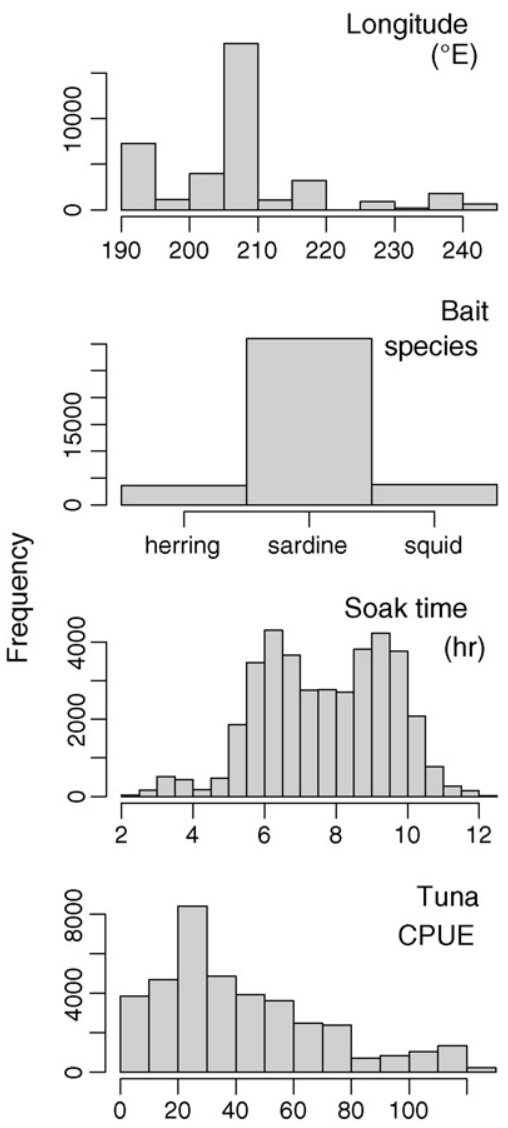

Table 1

Description of the longline fishing gear deployed by the 1950 s survey

\begin{tabular}{ll}
\hline Characteristic & Details \\
\hline Mainline material & Hard-lay cotton twine \\
Branchline material & 12 -strand cotton twine with wire leader \\
Level of fishing effort & 185 daily operations 48,249 hooks \\
Hooks per operation & 343 hooks $( \pm 269$ S.D.) \\
Hook type & $9 / 0$ or $8 / 0$ Mustad flattened tuna hooks \\
Lightsticks & No \\
Buoyline length & $19.2 \mathrm{~m}( \pm 6.42$ S.D.) \\
Branchline length & $20.7 \mathrm{~m}( \pm 7.02$ S.D.) \\
Hooks per buoy & Usually 6, ranging from 5 to 11 \\
Line shooter & No
\end{tabular}

Table entries are based on survey data supplemented with information from Murphy and Shomura (1972).

at dawn and retrieved in the afternoon. Usually, six hooks were attached to the mainline between each buoy, amounting to several hundred hooks in each daily fishing operation (Table 1).

Bait species included sardine (Sardinia melanosticta), squid (Loligo opalescens), and herring (Clupea pallasii). Missing operational details precluded the analysis of data from survey operations that deployed other bait species. Fresh, salted, or brined bait was occasionally used, but most was frozen (Fig. 1). Frozen bait was thawed and placed in rock salt or brine for several days to make it firm before deployment (Shomura, 1955). The survey tested several hooking methods, but we restricted our
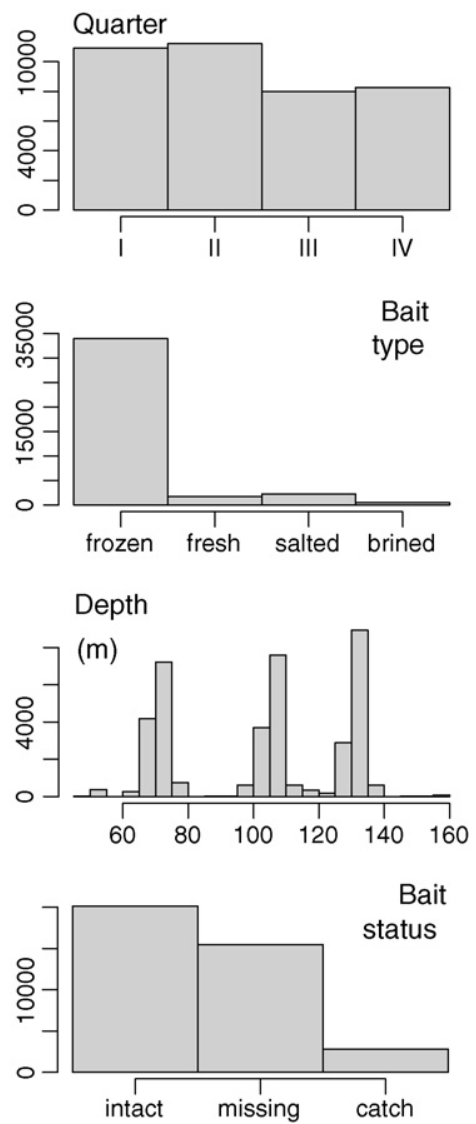

Fig. 1. Frequency histograms of variables in the survey dataset that were included in the final model $(N=36,829$ hooks). Tuna CPUE is the number of tuna per 1000 hooks. 
analyses to fish bait that were hooked through the head and squid bait that were hooked through the mantle, which is the practice on commercial longliners (Ward and Hindmarsh, in press).

Survey scientists recorded details of each longline operation (e.g., branchline length) and the time when each hook was deployed and retrieved, along with its status when retrieved (bait intact, bait missing, tangled branchline, or animal caught). We entered data for eight trips, consisting of 185 daily longline operations and 48,249 records of bait status, in the study area $\left(16^{\circ} \mathrm{S}-21^{\circ} \mathrm{N}, 119-170^{\circ} \mathrm{W}\right)$. The US NMFS Pacific Islands Regional Office now holds a copy of the dataset. For the analyses presented in this article, we classified remnant bait as "intact". Missing branchlines, tangled branchlines, and hooks that caught an animal were excluded from the analyses.

We estimated the soak time of each hook from survey records of the time when each hook was retrieved, combined with the start and finish times of longline deployment. The speed of longline deployment was assumed to be constant throughout each operation. We assumed that the mainline formed a catenary curve between each pair of floats and estimated the depth of each hook by applying the formula presented by Suzuki et al. (1977) to longline dimensions reported for each operation. The estimation of hook depth from the catenary formula provides only an approximation to the true depth of hooks (Bigelow et al., 2006), but we expect the estimates to represent the average depth distribution of hooks.

\subsection{Generalized estimating equations}

We used generalized estimating equations (GEEs; Zeger and Liang, 1986) to model bait loss rates. GEEs are a method for analyzing data that are collected in clusters where observations within a cluster may be correlated, but observations in separate clusters are independent (Halekoh et al., 2006). They can account for spatial and temporal correlations, which are common in fisheries data that do not adhere to strict sampling regimes (Bishop et al., 2000). Like generalized linear models (GLMs), GEEs allow for non-linear relationships between independent variables and the dependent variable (bait status), and accommodate the dependent variable's non-normal distribution.

The survey data consist of $i=1, \ldots, n$ daily longline operations ("clusters"), each consisting of $j=1, \ldots, m_{i}$ observations of the bait status of hooks $y$. The observations can be represented in vector notation as:

$y=\left(y_{1,1}, \ldots, y_{1, m_{1}}, \ldots, y_{i, 1}, \ldots, y_{i, m_{i}}, \ldots, y_{n, 1}, \ldots, y_{n, m}\right)$

We assumed that observations from different longline operations were independent, and that observations from hooks on the same longline followed an "arl" (autoregressive process with lag 1) correlation structure. The arl structure provides the highest correlation between observations for hooks that are close together along the longline and lower correlation for hooks that are further apart. Exchangeable and independence correlation structures resulted in a poorer fit to the data.
The expectations of bait loss $E(y)=\mu$ are related to the $p$ dimensional regressor vector $x_{i, j}$ by the mean-link function $g$ :

$g\left(\mu_{i, j}\right)=x_{i, j}^{t} \delta$

The parameter $\delta$ determines the shape of the relationship between the mean-link function and the regressor vector $(t$ indicates that this is the transposed matrix).

We assumed that the presence of a bait on each retrieved hook has a binomial distribution with $y \sim b(n, p)$, where $p$ is the probability of a bait being on a hook, $n$ is the number of hooks observed, and $g(\mu)=\mu(1-\mu)$ with $\mu \approx(0,1)$. For each hook $j$ in longline operation $i$, we linked the probability of a bait being present $p_{i, j}$ to a linear predictor $\eta_{i, j}$ through the logistic formula:

$p_{i, j}=\frac{e^{\eta_{i, j}}}{\left(1+e^{\eta_{i, j}}\right)}$

The linear predictor $\eta_{i, j}$ is the log odds of a bait being present on a retrieved hook. We modeled the log odds as a function of several covariates:

$$
\begin{aligned}
\eta_{i, j}= & \beta_{0}+\beta_{1} S_{i, j}+\beta_{2} B_{i, j}+\beta_{3} T_{i, j}+\beta_{4} D_{i, j}+\beta_{5} Y_{i} \\
& +\beta_{6} M_{i}+\beta_{7} Q_{i}+\beta_{8} E_{i}+\beta_{9} E_{i}^{2}+I_{i}
\end{aligned}
$$

where $S_{i, j}$ is the bait species (sardine, squid, or herring), $B_{i, j}$ the bait type (fresh, frozen salted, or brined), $T_{i, j}$ the soak time, and $D_{i, j}$ the estimated depth of hook $j$ in longline operation $i$; and $Y_{i}$ is the nominal catch rate of tunas, $Q_{i}$ the 3 -month quarter (i.e., season), $E_{i}$ the longitude, and $I_{i}$ is the unique identifier of longline operation $i$. The $\beta$ are estimated parameters.

The GEE model was implemented in the $R$ statistical language ( $R$ Development Core Team, 2006) using geeglm from library geepack (Yan and Fine, 2004). Model selection was based on the significance of the Wald statistic for each coefficient and the sum of squares of residuals (Pearson) divided by the residual degrees of freedom, which is considered a rough measure of fit for generalized estimating equations. We also fitted a generalized linear mixed effects model with the logistic formula (1) and a binomial distribution to the same dataset. The mixed effects model gave very similar results to the GEE model. We present results of the GEE model because its correlation structure matches the pattern of clustering in bait status expected along a longline and because it gave smaller standard errors for parameter estimates than the mixed model.

We used the final model to illustrate potential variations in fishing power for Japan's longliners in the study area during 1952-2004. For all three oceans, long time-series of catch and effort data reported by Japan's longliners are the prime abundance index for assessments of commercially important tuna species (Thunnus spp.) and several other major pelagic species, such as blue marlin Makaira nigricans). We created a synthetic time-series consisting of multiple longline operations of 3000 hooks for each year-quarter (Table 2). Within each year-quarter stratum, each hook was assigned a value for each model variable. Loss rates were then extrapolated from the final model and the synthetic time-series. 
Table 2

Sources of data for the synthetic time-series

\begin{tabular}{|c|c|c|c|}
\hline Variable & Stratification & Description & Source(s) \\
\hline Bait species & Year $\times$ quarter & $\begin{array}{l}\text { Bait species from published reports and observers } \\
\text { on Japanese longliners. }\end{array}$ & $\begin{array}{l}\text { Shimada (1951), Nakamura and Kamimura (1958), } \\
\text { JFA (1962-1980) })^{\text {,c }}, \text { Au (1986), Yamaguchi } \\
\text { (1989) }\end{array}$ \\
\hline Bait type & Year & $\begin{array}{l}\text { Bait type from published reports and observers }{ }^{\mathrm{a}} \text { on } \\
\text { Japanese longliners. }\end{array}$ & $\begin{array}{l}\text { Shimada (1951), Nakamura and Kamimura (1958), } \\
\text { (Yamaguchi and Kobayashi, 1974), Au (1986), } \\
\text { Yamaguchi (1989) }\end{array}$ \\
\hline Soak time & Year $\times$ hook & $\begin{array}{l}\text { Soak time of each hook estimated from observer } \\
\text { data and from published reports of longline } \\
\text { operation times. }\end{array}$ & Ward et al. (2004), Ward and Hindmarsh (in press) \\
\hline Depth & Year $\times$ hook & $\begin{array}{l}\text { Hook depths estimated from the catenary formula } \\
\text { applied to longline dimensions of Japanese } \\
\text { longliners in the tropical Atlantic Ocean. }\end{array}$ & Yokawa and Uozumi (2000) \\
\hline Tuna catch rate & Year $\times$ quarter & $\begin{array}{l}\text { Nominal catch rates reported by Japanese } \\
\text { longliners in the study area. }\end{array}$ & Miyabe (personal communication), SCTB (2004) \\
\hline Quarter & Year $\times$ quarter & $\begin{array}{l}\text { Three-month quarter weighted by the number of } \\
\text { hooks of Japanese longliners in the study area. }\end{array}$ & Miyabe (personal communication), SCTB (2004) \\
\hline Longitude & Year $\times$ quarter & $\begin{array}{l}\text { Longitude weighted by the number of hooks of } \\
\text { Japanese longliners in the study area. }\end{array}$ & Miyabe (personal communication), SCTB (2004) \\
\hline
\end{tabular}

\section{Results}

We explored various combinations of variables and interaction terms, and linear, quadratic, and cubic forms of each variable. Model selection also explored the effects of other variables, including latitude, month, moon phase, sea surface temperature, thermocline depth, the time of longline deployment and retrieval, the availability of bait at dawn and dusk, and catch rates of other taxonomic groups (e.g., sharks). However, those variables were not included in the final model because they did not explain significant variation or because they were highly correlated with other variables. Latitude and sea surface temperature were statistically significant in several models $(P<0.10)$, but they were not included in the final model because of correlations with other variables. The final model (2) used 36,829 of the 48,249 observations. All parameters in the final model were statistically significant $(P<0.076)$.

\section{Discussion}

Large quantities of bait were lost from longlines deployed by the 1950s survey. Predicted loss rates averaged 0.44 or $44 \%$ of baits deployed in the survey, where soak times averaged $7.78 \mathrm{~h}$. An extrapolation from the model when baits are initially deployed shows a loss rate that is greater than zero, i.e., the loss rate is 0.16 when soak time is $0.0 \mathrm{~h}$. It is not unusual to observe high initial loss rates during deployment. In an analysis of research vessel data from the North Pacific salmon fishery, Shepard et al. (1975) attributed high initial loss rates $(0.25)$ to inadequate attachment of bait to hooks and the agitation of the longline during deployment. High initial loss rates might also be due to elevated attacks on baits and hooking rates for sev- eral species during longline deployment, as reported by Boggs (1992).

We could not determine exactly when bait was lost during longlining operations; whether it was lost during deployment, during the soak, or during retrieval. Our model will overestimate the effect of soak time on loss rates if bait is lost during retrieval. However, model selection showed that quadratic and cubic coefficients for soak time were not statistically significant $(P>0.10)$, indicating that loss rates during retrieval were not particularly high. Hook-timers placed on longlines have begun to provide information on the time when an animal is hooked and also whether it is subsequently lost (Boggs, 1992). Nevertheless, those studies do not indicate whether animals removed baits, whether an animal was hooked but then escaped, or whether the bait fell off the hook.

Removals by scavengers or target species, disintegration, and physical stresses from wave action and longline deployment and retrieval, are common causes of bait loss (Shomura, 1955). The variables included in our model are proxies for those three mechanisms. Our analyses show that soak time, bait species, and depth had the greatest effects on loss rates (Table 3; Fig. 2). Loss rates increased with soak time, probably as a result of a combination of all three mechanisms. Loss rates for squid bait were low, confirming observations by other authors that firm-fleshed bait are less likely to be torn from hooks by scavengers or break apart and fall off hooks than are soft-bodied species (Shomura, 1955). Our analyses did not show a statistically significant difference $(P>0.36)$ between loss rates for fresh, frozen and salted bait. Only the loss rates of brined bait were significantly higher than the other bait types $(P<0.001)$. Note, however, that survey scientists fully thawed bait before deployment. 
Table 3

Parameter estimates and statistics for the final model of bait loss

\begin{tabular}{lrlcl}
\hline Coefficient & Estimate & S.E. & Wald statistic & $P(>W)$ \\
\hline Intercept & -33.596 & 9.538 & 12.4058 & 0.0004 \\
Tuna CPUE & -0.0023 & 0.0013 & 3.1513 & 0.0759 \\
Quarter II & 0.2799 & 0.1456 & 3.6970 & 0.0545 \\
Quarter III & -0.2457 & 0.1296 & 3.5960 & 0.0579 \\
Quarter IV & 0.3206 & 0.1544 & 4.3124 & 0.0378 \\
Soak time & -0.1241 & 0.0161 & 59.3977 & 0.0000 \\
Depth & 0.0087 & 0.0006 & 186.5607 & 0.0000 \\
Longitude & 0.2919 & 0.0903 & 10.4485 & 0.0012 \\
Longitude $^{2}$ & -0.0006 & 0.0002 & 9.2107 & 0.0024 \\
Bait species sardine & 1.5170 & 0.1798 & 71.2162 & 0.0000 \\
Bait species squid & 2.1195 & 0.2587 & 67.1172 & 0.0000 \\
Bait type fresh & -0.0182 & 0.1625 & 0.0125 & 0.9109 \\
Bait type salted & -0.1495 & 0.1633 & 0.8385 & 0.3598 \\
Bait type brined & -0.8094 & 0.1892 & 18.2995 & 0.0000 \\
\hline
\end{tabular}

Previous studies of bait loss in demersal fisheries show that loss rates increase with water depth (Skud, 1978). By contrast, our analyses show that loss rates from pelagic longlines decrease with hook depth. The high loss rates on shallow hooks might be due to the mechanical effects of surface waves. Several longline
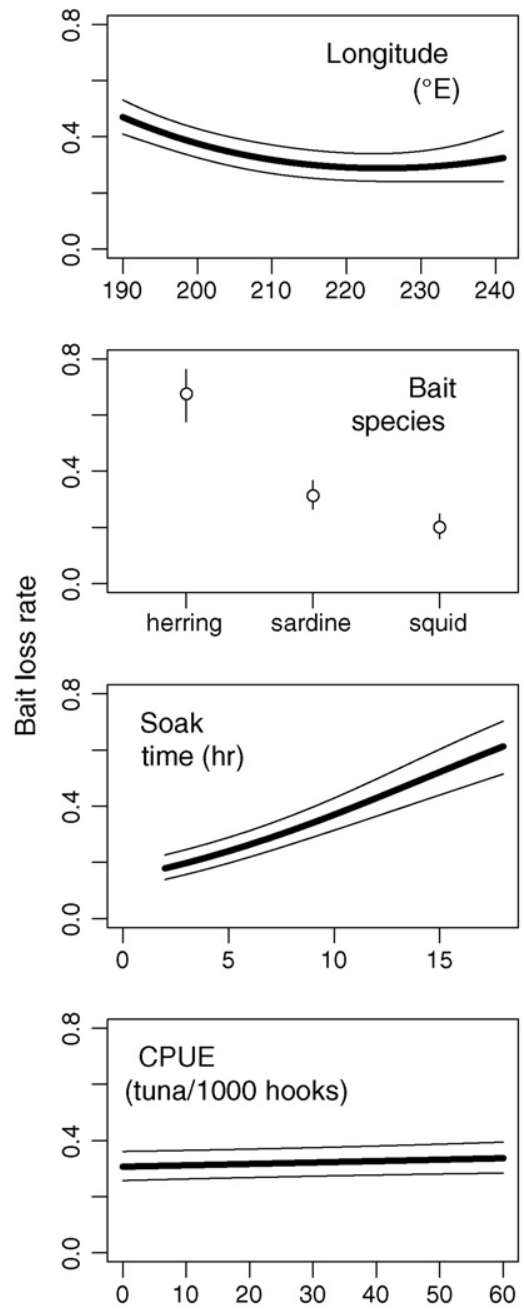
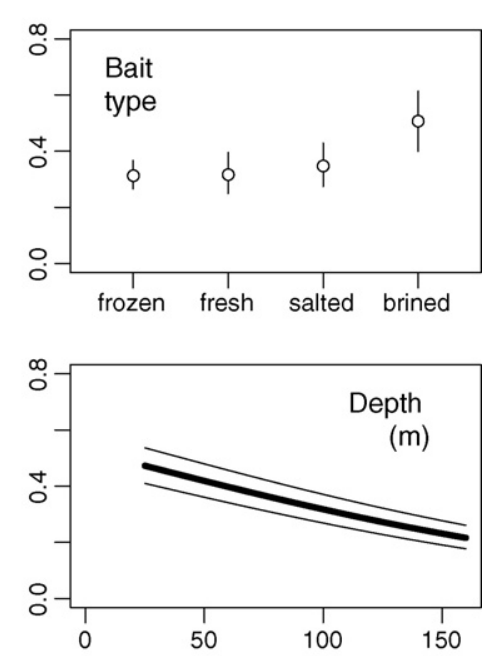

fishers and observers that we contacted believed that loss rates are high during rough weather. Turbulence, which is a function of wind velocity, declines with depth (Niiler and Kraus, 1977), so that bait may be more likely to be lost from shallow hooks. However, we were unable to obtain adequate data to model the effects of ambient wind velocity on loss rates. We fitted a generalized linear model with a normal error distribution to mean monthly wind velocity in the study area during 1957-2003 (ECMWF, 2006). The model's month coefficient was highly significant $(P<0.001)$, but the year coefficient was not significant $(P>0.845)$. We conclude that, regardless of the effect of wind on loss rates, bait loss caused by turbulence would not have influenced fishing power in the long-term.

Removals by scavengers, like wahoo (Acanthocybium solandri), and target species that are active near the sea surface may also contribute to high loss rates on shallow hooks. Small scavengers and predators, including tuna, billfish, sharks, and cetaceans, are reported to remove bait from longlines. Shomura (1955), for example, reported that $84.5 \%$ of the stomachs of 822 large tuna contained no bait, $13.6 \%$ contained one bait, and $1.8 \%$ contained two or more baits. One yellowfin tuna (Thunnus albacares) contained nine baits. Shomura's observations are
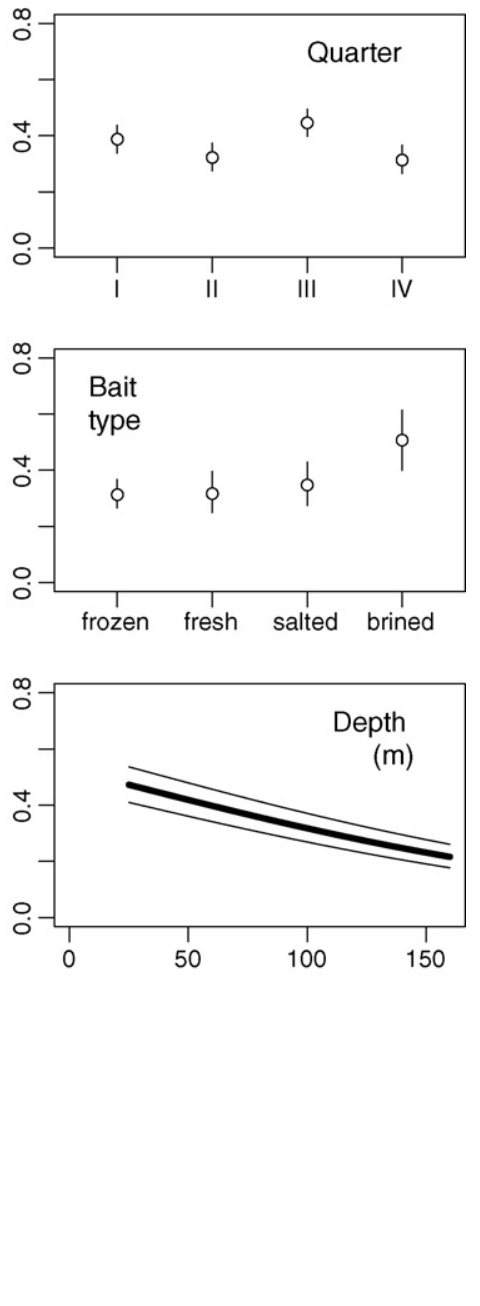

Fig. 2. Model predictions of bait loss. We used the final model to predict loss rates over the range of each variable while holding other variables constant at their mean value in the dataset. Heavy lines are mean predictions (light lines are approximate $95 \%$ confidence intervals). 
consistent with our results, which show that tuna catch rate affected loss rates. Tuna catch rate is a proxy for the local abundance of tuna. However, it may be confounded with the observations of bait loss, because loss rates will affect those catch rates.

Several factors that were not included in our model might affect loss rates. Thermocline depth, moon phase, month, sea surface temperature, and the availability of hooks at dawn or dusk, were not included in the final model because they did not significantly affect loss rates $(P>0.10)$. The activities of scavengers should vary with the time of day, season, illumination in the water column, and ambient temperature. Time of day was not statistically significant in our model $(P>0.10)$, probably because survey longlining rarely extended into night. However, several longline fishers and observers that we contacted believed that loss rates are high at night when scavengers, like squid, are active in the mixed layer. The timing of longlining operations is also known to affect catch rates of several species, probably as a result of increased feeding activity of many predators during crepuscular periods (Maéda, 1967; Ward et al., 2004). The timing of operations may also affect bait loss rates in swordfish fisheries, which deploy longlines at night, and in tuna fisheries that have progressively increased the availability of baited hooks after dusk (Ward and Hindmarsh, in press).

It is unclear why loss rates declined with longitude. The significance of longitude might be related to east-west gradients in oceanographic conditions (e.g., thermocline depth) or variations in animal communities. Investigations of loss rates in other pelagic longline fisheries would broaden our understanding of the effects of biological and environmental conditions on loss rates. Seabirds are known to steal bait during longline deployment and retrieval at high latitudes (Brothers, 1991). Measures, such as bird-scaring "tori” lines, thawed bait, and nighttime longline deployment, have been instituted to reduce the bycatch of seabirds since the early 1990s (Ward and Hindmarsh, in press). Such measures will also reduce the removal of bait by seabirds. Løkkeborg and Robertson (2002), for example, reported that bird-scaring lines reduced loss rates by 13-14\% during deployment of demersal longlines off Norway.
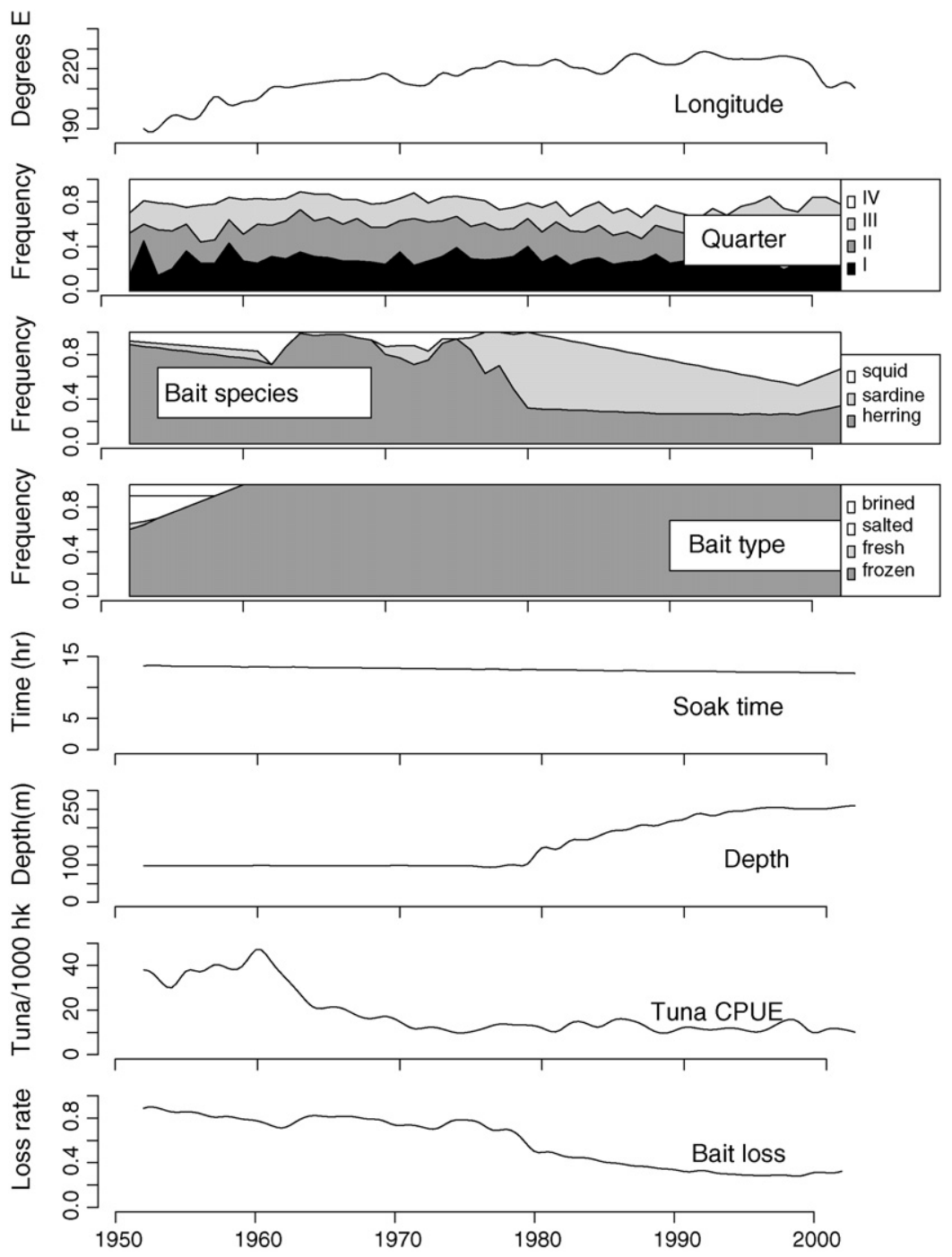

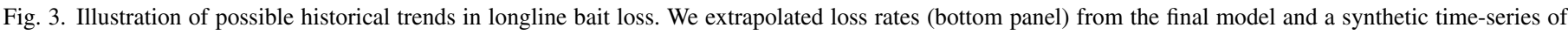
values for each variable. The upper panels show annual means for each variable in the synthetic time-series. 
Murphy (1960) and others have developed catch equations for adjusting longline catch rates for soak time, bait loss, gear saturation, hooking, and escape. The results of our analyses combined with data from hook-timers and observer or survey data on the catch on each hook almost complete the parameter estimates required to solve such equations. Escape rate is the only parameter that has not been studied in pelagic longline fisheries. Hook-timer experiments often retrieve large numbers of triggered hook-timers without catching an animal (Boggs, 1992). It is often unclear, however, whether the triggering of hook-timers was due to equipment malfunction or whether it indicates high escape rates. Escape rates could be estimated through direct observation (e.g., underwater cameras), although large sample sizes are required because of the apparently low rates of interaction between animals and longlines in the open ocean.

We do not discuss the actual values of extrapolated loss rates because of uncertainties in using a model that is based on data collected 50 years ago and extrapolation outside the range of data used in model development. Increased depth range, a switch to squid bait, an eastwards shift in the centre of longlining activity, and decreased tuna abundance contributed to a hypothesised increase in fishing power until the late 1990s (Fig. 3). It is unlikely that other changes in longline fishing power would balance the increases caused by reduced bait loss. Ward and Hindmarsh (in press), for example, identify several major changes in pelagic longline gear and practices since longlining commenced, all contributing to increased fishing power and catchability.

Loss rates since the early 1950s and among fisheries might vary from the extrapolated levels depending on bait treatment. During the survey, bait was soaked in brine for a several days before deployment, which is not the practice in contemporary longline fisheries. Other variables that were not included in the model, or which had limited contrast in the survey dataset, may also influence loss rates among fisheries and over time. These include variations in fishing gear (e.g., hook design and leader material), fishing practices (e.g., operations that extended into night), the physical environment (e.g., the Pacific Decadal Oscillation), and the biological environment (e.g., abundance of scavengers).

Our results imply that the depletion of tuna populations will cause small but significant reductions in loss rates. Those declines are likely to be greater than indicated by the catch rates used in this analysis because they do not take into account various improvements in technology (Ward and Hindmarsh, in press). The resulting increase in fishing power might result in a pattern of hyperstability where nominal catch rates are maintained by an increase in fishing power as abundance declines (Hilborn and Walters, 1992). Less competition among target species for bait would increase catchability and further add to hyperstability (Sinoda, 1981; Au, 1986). On the other hand, the removal of large pelagic predators in the 1950s may have resulted in predator release - an increase in the abundance of small species as predation declined (Ward and Myers, 2005c). An increase in the abundance of scavengers, which are mostly small species, might result in increased bait loss and reduced fishing power. Further work is required to determine whether predator release has resulted in reduced fishing power or whether the removal of large predators has resulted in increased fishing power and hyperstability.

\section{Conclusions}

This article provides a baseline for a relatively unexploited fishery, highlighting the importance of compiling and analyzing more information on bait loss so that historical trends in fishing power can be estimated. Several factors shown to affect loss rates, such as hook depth and bait species, have varied over the historical time-series of catch and effort data that is used to derive abundance indices for assessments. Further work is required to quantify historical trends in those variables and to identify other variables that have a significant influence on loss rates.

\section{Acknowledgements}

Grants from the Pew Charitable Trust, Pelagic Fisheries Research Program, and the Killam Foundation supported this work. Bert Kikawa provided copies of the original data sheets. David Gill and Sheree Hindmarsh helped to enter data. Karine Briand, David Kirby, and Brent Miyamoto assisted with oceanographic data. Steve Auld and Jay Hender provided observer and fisher information. Bill Clark gave advice on longline surveys. Wade Blanchard provided advice on statistical analyses. Three anonymous referees provided comments on the manuscript.

\section{References}

Au, D., 1986. Interpretation of longline hook rates. SCRS/87/47. In: Collective Volume of Scientific Papers, vol. 25. International Commission for the Conservation of Atlantic Tunas, Madrid, Palma de Mallorca (Spain), pp. 377-385.

Beverton, R.J.H., Holt, S.J., 1957. On the Dynamics of Exploited Fish Populations. Fishery Investigations Series 2, vol. 19. Great Britain Ministry of Agriculture and Fisheries, London.

Bigelow, K., Musyl, M.K., Poisson, F., Kleiber, P., 2006. Pelagic longline gear depth and shoaling. Fish. Res. 77, 173-183.

Bishop, J., 2006. Standardizing fishery-dependent catch and effort data in complex fisheries with technology change. Rev. Fish. Biol. Fish. 16, 21-38.

Bishop, J., Die, D., Wang, Y.-G., 2000. A generalized estimating equations approach for analysis of the impact of new technology on a trawl fishery. Aust. N. Z. J. Stat. 42, 159-177.

Boggs, C.H., 1992. Depth, capture time, and hooked longevity of longlinecaught pelagic fish: timing bites of fish with chips. Fish. Bull. 90, 642-658.

Brothers, N., 1991. Albatross mortality and associated bait loss in the Japanese longline fishery in the Southern Ocean. Biol. Conserv. 55, 255-268.

Deriso, R.B., Parma, A.M., 1987. On the odds of catching fish with angling gear. Trans. Am. Fish. Soc. 116, 244-256.

ECMWF, 2006. Re-analysis ERA-40 [online] European Centre for Medium-range Weather Forecasts. Available from http://www.ecmwf.int/ products/data/archive/finder.html 21 August 2006.

Halekoh, U., Højsgaard, S., Yan, J., 2006. The R package geepack for generalized estimating equations. J. Stat. Software 15, 1-11.

Hilborn, R., Walters, C.J., 1992. Quantitative Fisheries Stock Assessment: Choice, Dynamics and Uncertainty. Chapman and Hall, New York.

JFA, 1962-1980. Annual Report of Effort and Catch Statistics by Area on Japanese Longline Fishery. Research Division, Fisheries Agency of Japan (JFA), Nankai (Japan). 
Løkkeborg, S., Robertson, G., 2002. Seabird and longline interactions: effects of a birdscaring streamer line and line shooter on the incidental capture of northern fulmars Fulmarus glacialis. Biol. Conserv. 106, 359-364.

Maéda, H., 1967. Distribution pattern of fish in relation to fishing method, with special reference to that of tuna along longline. In: Symposium on Scombroid Fishes, Part III. Symp. Ser. Mar. Biol. Assoc. India 1, pp. 1025-1041.

Maunder, M.N., Punt, A.E., 2004. Standardizing catch and effort data: a review of recent approaches. Fish. Res. 70, 141-159.

Murphy, G.I., 1960. Estimating abundance from longline catches. J. Fish. Res. Board Can. 17, 33-40.

Murphy, G.I., Shomura, R.S., 1972. Pre-exploitation abundance of tunas in the equatorial central Pacific. Fish. Bull. 70, 875-913.

Nakamura, H., Kamimura, T., 1958. Investigations of tuna fishing grounds. In: Report of Toko Maru Investigations on the Fishing Grounds in the Atlantic Coast of the Central and South America (October 1956-July 1957). Japan Fisheries Agency, Tokyo.

Niiler, P.P., Kraus, E.B., 1977. One-dimensional models of the upper ocean. In: Kraus, E.B. (Ed.), Modelling and Prediction of the Upper Layers of the Ocean, pp. 143-172.

Pingguo, H., 1996. Bait loss from bottom-set longlines as determined by underwater observations and comparative fishing trials. Fish. Res. 27, 29-36.

$R$ Development Core Team, 2006. $R$ : a language and environment for statistical computing. R Foundation for Statistical Computing, Vienna, Austria. Available from http://www.R-project.org.

SCTB, 2004. Standing Committee on Tuna and Billfish (SCTB), Tuna Fishery Statistics Public Domain Data [online] Secretariat of the Pacific Community, Noumea. Available from http://www.spc.int/oceanfish/ Html/Statistics/Index.htm 9 June 2007.

Shepard, M.P., Roberts, R.F.A., Aro, K.V., Turner, C.E., 1975. Effect of bait loss on catching power of floating longline gear. Bull. Int. North Pacific Fish. Comm. 32, 71-77.

Shimada, B.M., 1951. Japanese Tuna-Mothership Operations in the Western Equatorial Pacific Ocean. U.S. Fish and Wildlife Service, Fishery Leaflet No. 284 13, 1-26.

Shomura, R.S., 1955. A Comparative Study of Longline Baits. U.S. Fish and Wildlife Service. Special Scientific Report: Fisheries, Washington.

Sigler, M.F., 2000. Abundance estimation and capture of sablefish (Anoplopoma fimbria) by longline gear. Can. J. Fish. Aquat. Sci. 57, 1270-1283.
Sinoda, M., 1981. Competition for baited hooks in a mulitple species fishery. Bull. Jpn. Soc. Sci. Fish. 47, 843-848.

Skud, B.E., 1978. Factors affecting longline catch and effort: III. Bait loss and competition. International Pacific Halibut Commission, Scientific Report No. 64, Seattle.

Sullivan, P.J., Rebert, S., 1998. Interpreting Pacific halibut catch statistics in the British Columbia individual quota program. Can. J. Fish. Aquat. Sci. 55, 99-115.

Suzuki, Z., Warashina, Y., Kishida, M., 1977. The comparison of catches by regular and deep tuna longline gears in the western and central equatorial Pacific. Bull. Far Seas Fish. Res. Lab. 15, 51-89.

Ward, P., Hindmarsh, S. An overview of historical changes in the fishing gear and practices of pelagic longliners. Rev. Fish. Biol. Fish. 17 (4), in press.

Ward, P., Myers, R.A., 2005a. A method for inferring the depth distribution of catchability for pelagic fishes and correcting for variations in the depth of longline fishing gear. Can. J. Fish. Aquat. Sci. 62, 1130-1142.

Ward, P., Myers, R.A., 2005b. Do habitat models accurately predict the depth distribution of pelagic fishes? Fish. Oceanogr. 14, 1-7.

Ward, P., Myers, R.A., 2005c. Shifts in open ocean fish communities coinciding with the commencement of commercial fishing. Ecology 86, 835847.

Ward, P., Myers, R.A., Blanchard, W., 2004. Fish lost at sea: the effect of soak time and timing on pelagic longline catches. Fish. Bull. 102, 179195.

Yamaguchi, Y., 1989. Tuna long-line fishing II: fishing gear and methods. Mar. Freshwater Behav. Physiol. 15, 13-35.

Yamaguchi, Y., Kobayashi, H., 1974. Studies on the appearance of empty hooks-III. On the simultaneous occurrence of empty hooks and hooked fish, and the occurrence of spoiled baits and hooked fish. Nihon Suisan Gakkai shi (Bull. Jpn. Soc. Sci. Fish.) 40, 119-128.

Yan, J., Fine, J.P., 2004. Estimating equations for association structures. Stat. Med. 23, 859-880.

Yokawa, K., Uozumi, Y., 2000. Analysis of Operation Pattern of Japanese Longliners in the Tropical Atlantic Ocean and their Blue Marlin Catch, vol. 53. International Commission for the Conservation of Atlantic Tunas, Madrid, pp. 318-336.

Zeger, S., Liang, K.Y., 1986. Longitudinal data analysis using generalized linear models. Biometrics 73, 13-22. 